\title{
Risk Management and Adaptation Transitions in New York City
}

\author{
William Solecki*, ${ }^{*}$, Hildegaard Link ${ }^{\dagger}$ and Matthias Garschagen ${ }^{*}$ \\ *Department of Geography and CUNY Institute for Sustainable Cities \\ Hunter College - City of New York \\ 695 Park Avenue, New York, NY 10065, USA \\ Earth and Environmental Science Program \\ City University of New York - Graduate Center \\ 365 Fifth Avence, New York, NY 10016, USA \\ ${ }^{*}$ Risk Management and Adaptive Planning (VARMAP) \\ United Nations University \\ Institute for Environment and Human Security (UNUEHS) \\ UN Campus, Platz der Vereinten Nationen 1 \\ D-53113 Bonn, Germany \\ \$wsolecki@hunter.cuny.edu
}

Published 8 March 2017

Local risk managers in New York City were keenly aware that the city's residents, businesses, and infrastructure were vulnerable to significant flooding events before Hurricane Sandy hit in October 2016. The storm and its aftermath have influenced the structure of the city's approach to risk management and urban development in many ways. The objective of this manuscript is to characterize the current risk management regime in New York City, how it is changing, and how it might shift with the further onset of climate change. More specifically, the paper addresses three basic questions: 1 . How does current risk management policy in New York City intersect with climate change adaptation and urban development?; 2. Is there sentiment that transition to a new risk management paradigm is needed?; and 3. If transition is necessary, how will it be enabled or blocked by the current actors, organizations and policy-making networks for adaptation and risk management in the city? In the analysis we focus on examining the relative importance of a suite of possible factors and drivers. Two sources of data are reviewed and integrated. These include results from a workshop with local risk managers, and as well as face-to-face extended interviews with risk manager stakeholders and practitioners. The results indicate that there is significant need for a transition to wider and more comprehensive transformative adaptation policy but the means and opportunities to do is limited.

Keywords: Risk management regime; policy transition; flooding; heat extremes. 
We will need to embrace the notion of change, there will have to be really tough discussions about what does quality of life look like for New Yorkers NYC stakeholder discusses the implication of climate change, early 2016.

\section{Introduction}

Risk management regimes evolve in communities as bureaucrats and residents attempt to reduce vulnerability to hazards and limit the scope of disasters. The overarching goal these regimes are to try to reduce the level of risk faced by residents, resources, and economic interests in a particular locale. The conditions and evolving character of the local risk management regime and transition is complex and is affected by a variety of physical and social factors and drivers (Solecki et al. 2017; Pelling 2011). Risk management is characterized by understanding local hazards and vulnerabilities but is also set within the larger economic development trajectory of a region. Opportunities and barriers to meaningful action and potential advancement are found at this nexus (Pelling et al. 2016).

To illuminate these issues, this paper provides a detailed discussion and analysis of the New York City risk management regime and its trajectory as defined by local experts. The discussion seeks to provide insight into characteristics of risk management and development regimes ${ }^{1}$ in New York and to define the scope for regime transition in New York City. It combines work from an expert workshop where risk managers working in New York City discussed the interaction of development and risk management, with a series of interviews with New York City risk management sectorial experts. The overarching line of inquiry in this paper is concerned with the change in the urban adaptation regime in New York City. The specific focus of the analysis is storm surge and flooding, and heat stress. The analysis examines the factors that enable movement and transition between different adaptive regimes, and on factors that support lock-in of current regime status. The paper attempts to address three basic research questions:

- How does current risk management policy in New York City intersect with climate change adaptation and urban development?

- Is there sentiment that transition to a new risk management paradigm is needed among New York City sectorial expert project participants?

\footnotetext{
${ }^{1}$ Based on the definition of TRUC Working Paper 2, a risk management regime in this paper refers to a "an established set of institutions, norms, and behaviors organized in such a way to promote established patterns of preparedness, response, and recovery” (Pelling and Solecki, 2015: p. 2).
} 
- If transition is necessary, how will it be enabled or blocked by the current actors, organizations and policy-making networks for adaptation and risk management in the city?

The research utilizes a risk management framework developed for the Transformation and Resilience in the Urban Coast (TRUC) project (Solecki et al. 2017). At the core of the framework are four policy states that help to grasp the extent to which urban risk management can contribute toward the aspiration of sustainable development. $^{2}$ "Collapse" describes a state where there is no strategic risk planning; "resistance" refers to risk planning that is directed at stability and aims at protecting current development pathways; "resilience" refers to flexible planning that aims at introducing some changes to maintain current development, and "transformation", which refers to planning for fundamental changes in risk management including changing development choices and paths to accommodate uncertainty and future risk scenarios (Solecki et al. 2017).

This paper is divided into several sections. The following, second, section briefly introduces the development and risk management history of New York City. In Section 3, we introduce the methodology and approach to the analysis with a discussion of the data collection and analysis. Sections 4 and 5 respond directly to the research questions. We examine the current dominant risk and adaptation regime in New York City and then trace pathways and prospects for regime change in risk management in New York City. The conditions of transformational regime adaptation in New York City are presented as the factors that enable movement or lock-in of the current regime. The paper closes with a brief discussion and conclusion.

\section{History of Development and Risk Management in New York City}

Prospects of transition to more transformative adaptation regimes in current day New York City are shaped by the city's long and complex history of development and its connection to the waterfront and the coast. Root drivers of adaptation regime change include economic and cultural aspects of the city's history that continue to influence strategic policy making. Many of the drivers of risk management behavior in NYC can be traced to its position as first a major port city and later as a global finance center.

\footnotetext{
${ }^{2}$ Following TRUC Working Paper 2, sustainable development in this paper refers to a development vision, policy, and practice that is directed at meeting at least "minimum standards for human security (basic needs and human rights) without exceeding ecological and biophysical limits" (Pelling and Solecki 2015: p. 1).
} 
Urban settlement in New York City stretches back over four centuries. New York City's history is characterized and shaped by tides of immigration and technological changes and continuous visioning and re-visioning of land use. Land use change has been particularly volatile over the centuries along shoreline of the towns and villages that make up what are today the five boroughs (i.e., US counties) of New York City. New York City is located at the mouth of the Hudson River. The five boroughs of the city cover multiple islands in the Hudson River estuary. New York's city center, Manhattan, is an island unto itself. Brooklyn and Queens are located on the western end of Long Island and include several lesser islands and sand bars. Staten Island is also an island borough. While the Bronx is the only NYC borough that is not an island, it is surrounded by tidal water on three sides. New York City grew along its shoreline and as a result many of the most significant or historic properties, highest population densities and most critical infrastructure are near the water's edge.

The history of waterfront development and the waterfront concentration of population, business and high value real estate is pivotal to the risk management regime tensions in NYC.

The docks and port in New York City were key to the economic success of New York City and the region, as an international distribution locus for goods coming from all over the world. To this day, the heart of New York's financial industry is concentrated in lower Manhattan (i.e., the Wall Street area) just a short walk from the colonial era port. Real estate property values in this area are among the highest in the world. The financial service industry fostered the growth of the city as international economic citadel. It is this primate global city position (Sassen 2005) that undergirds much of the risk management tension revealed in our research. The 9/11 terror attacks and Hurricane Sandy disrupted the functioning of the financial service companies in lower Manhattan. Significant efforts have been taken to lessen the vulnerability of the area to similar shocks in the future.

Overall, the New York City risk profile is a combination of high value real estate, a concentration of high net worth population and vulnerable physical infrastructure in the central city paired with diminishing property values, diminishing density and diminishing affluence moving away from Manhattan and into the outer boroughs (http://www.businessinsider.com/new-york-city-income-maps-2014-12). The only constant is the vulnerability of critical infrastructure to flooding and tidal inundation. All over the city, many physical and economic assets are exposed to risk of flooding. From power plants, electrical substations and subway stations to hospitals and wastewater treatment plants, New York City has sited essential services on the waterfront in high-risk evacuation zone one. Flooding is a risk to almost every element of critical city infrastructure. 
A second and more mundanely deadly aspect of the New York City risk profile is heat. Summertime heat waves are locally defined as three days or more consecutive days when the temperature rises over $90^{\circ} \mathrm{F}\left(\sim 32.2^{\circ} \mathrm{C}\right)$. High temperatures and summertime humidity can lead to heat index values of more than $100^{\circ} \mathrm{F}$ and coupled with elevated overnight temperatures can lead to heat stress for residents and critical infrastructure. Extreme heat waves in New York are associated with heat-related illnesses and deaths, peak load electricity demand for air conditioning and a range other heat-related stresses on infrastructure. Because of the very high concentration of masonry structures, the city is subject to the urban heat island effect (Gaffin et al. 2008). During the summer months, parts of the city are up to $3^{\circ} \mathrm{C}$ warmer than the surrounding suburbs. High temperatures take the largest toll in non-affluent communities where access to air conditioning is limited. The very old, the very young, and otherwise health challenged are the most vulnerable. In the context of increasing development, climate change and increasing regional temperatures, life threatening extreme heat events could become more frequent. Current patterns of development, planning for future development and the potential for climate change based increases in regional temperatures make heat and flood risk in the city of interest to this study (Tan et al. 2010).

\section{Methods and Research Approach}

Two sources of data were developed and utilized to address the research questions about current and potential future risk management conditions in New York City. The first dataset was gathered from a daylong workshop on risk management and resilience. The second dataset was gathered from a set of 21 interviews with key risk management stakeholders across from a cross-section of New York City agencies, organizations, and academic institutions.

\subsection{Workshop methodology}

The workshops convened key New York City (NYC) stakeholders. ${ }^{3}$ Stakeholders included a range of technical staff and decision makers from the New York City Government, NGOs and academia working on urban development and risk management. The goal of the workshop was to develop a risk management assessment tool based on key development concerns for the NYC mega-region and applicable adaptation regimes. The workshop approach was directly derived from Garschagen et al. (2017).

\footnotetext{
${ }^{3}$ The organization and implementation of the workshops was supported by CUNY within the TRUC consortium (Garschagen et al. 2017).
} 
Table 1. Study Sample by Organization

\begin{tabular}{llc}
\hline Organization & \multicolumn{1}{c}{ Administrative Scale } & \# of Interviews \\
\hline New York City local authority & Local & 8 \\
New York State & State wide (NYC region) & 1 \\
US Government & National (NYC region) & 1 \\
Not For Profit & Regional (New York City) & 5 \\
Utilities/Critical Infrastructure & Regional (New York City) & 2 \\
Academic & n/a & 3 \\
Private Sector & International & 1 \\
& & Total 21 \\
\hline
\end{tabular}

\subsection{Expert interviews methodology}

Data for this portion of the analysis is taken from 21 semi-structured expert interviews with risk management professionals in New York City. Interviews were conducted between November 2015 and March 2016. The data gathered through the expert interviews provide insights on climate change adaptation in New York City. The experts interviewed offered their opinions on the prospects of and limits to changes in both disaster risk management and larger development trajectories in the city. It provides information on the sensitivity in urban risk management as one component of the character and evolution of urban coastal socio-ecological systems (SES), which are formed by the hazard (data collected through TRUC biophysical model) and by local susceptibility (data collected through TRUC household survey).

An overview of the sample indicating the type of stakeholders, the administrative scale they operated at, and the number of interviews is shown in Table 1. Participants were identified based on available contacts, both from participation at the TRUC New York City workshop in May 2015 discussed above, and from an existing network of contacts from earlier research on heat wave risk management in New York City. In total, 27 individuals were approached for participation in the study. Potential participants were contacted via email. The email introduced the TRUC project and featured an information sheet that summarized the most relevant aspects of the research work and provided contact information. All interviews were conducted using the TRUC expert survey. Details of the methodology can be found at the TRUC project website. ${ }^{4}$ The survey was structured in five sections, capturing background information on the respondent's professional role, the current risk

\footnotetext{
${ }^{4}$ A full copy of the survey can be found at the TRUC website - http://www.bel-truc.org/. The TRUC expert survey is the standardized data collection tool in all TRUC case studies.
} 
management regime in the city, the risk management status, future risks and potentially related risk management regime changes, and conclusions. It featured a mixture of closed and open questions. Closed questions asked respondents to choose from a range of pre-specified answers. Open questions provided opportunities for respondents to clarify and elaborate on particular aspects of the closed questions. The qualitative analysis of the responses given by interviewees is complemented by descriptive statistics from closed questions that aim to provide an overview of the range of responses.

Potential biases in the analysis stem in particular from the selective sampling strategy. Additional biases may have evolved from the 13 November 2015 Paris terror attacks, which took place at the outset of the data collection process or political orientation of participants that was not controlled for. Many opined on organizational and social change processes driven by policy, and necessarily shaped by political parties and party agendas.

\section{Results and Discussion}

\subsection{Current risk management and connections between climate adaptation and urban development}

The first research question to be addressed focuses on how does the current risk management in New York City intersects with on going discussion of climate change adaptation and urban development in the city. The workshop data and the interview data converged to provide similar and validating results. Major drivers of vulnerability and socio-economic development identified during the workshop are shown in Table 2 below.

These drivers range from geophysical processes to administrative and institutional factors. Several participants mentioned the role of urban spatial planning as contributing negatively. Poor planning was perceived to have helped foster current vulnerability trends. Similarly, social inequality and poverty were prominent in the discussion, either explicitly mentioned as drivers of current vulnerability or as

Table 2. New York City - Drivers of Vulnerability and Socio-Economic Development

\begin{tabular}{ll}
\hline - Heat & - Food Security \\
- Data/access to data (see footnote 1) & - Flood insurance (see footnote 1) \\
- Planning (see footnote 3)/real estate development & - Risk awareness \\
- Social housing (see footnote 1) & - Mitigation \\
- Economic and social inequity (see footnote 2) & - Economic actors/private actors \\
- Encouraging housing in flood zones & - Participation \\
- Community inequality & - Government (integration and \\
- Infrastructure & collaboration) \\
\hline
\end{tabular}


undercurrents connecting other drivers such as inequalities in health care systems or access to public goods.

New York City workshop participants placed great emphasis on the ability of urban economies to steer their development trajectories. The debate focused little on the implications of national economics and more on the growth and business models of the city. Participants questioned whether city growth and business models would be sustainable and robust in the long-term. Vulnerability implications of existing New York growth and business models was also a topic of concern. These concerns raise many questions about assigning which agency(ies) and organization(s) could most effectively shape urban development and adaptation trajectories. Of particular interest is the question, to what extent can urban development and adaptation trajectories be piloted or even turned via in-city decision making versus by external forces. Each center of decision-making lacked the fundamental capacity to significantly alter or change the development and adaptation trajectories.

In the workshop, regimes of risk insurance were mentioned as main drivers for current and future vulnerability trends in New York City. Insurance payout practices were of particular concern vis-a-vis future vulnerability. Misguided incentives were mentioned as a major risk driver. In New York City, residential development in flood zones has been incentivized over the past decades by insurance and Federal Emergency Management payouts based on an imbalanced preoccupation with the economic values that may be realized in these locations.

Participants also gave substantial weight to public housing schemes. Insufficient heat and flood planning in public housing was perceived of as a major driver of social vulnerability. The intersection of pressure to build public housing inexpensive and ineffective flood zoning was identified as a particularly problematic nexus of social inequality and climatic vulnerability in the city. The overall workshop results were organized and presented in graphical form with two key axes. The process of defining the specific character of the $x$-axis was co-generated amongst the stakeholders with the facilitator, as were the identifying characteristics of each quadrant. Table 3 presents the overall workshop output matrix.

The workshop results identified four quadrants. Besides the central adaptation axis, the workshop participants identified a development axis focused on equity and governance capacity. The participants felt there was disconnect between the current interaction between the current conditions of the adaptation-development nexus and to what they aspire. The partners felt that a variety of factors linked direct and indirect feedbacks associated with an emphasis on individual action as opposed to collective action, lack of public funding for long-term adaptation efforts, increasing vulnerability, and exposure of population to climate change. 
Table 3. Adaptation — Development Nexus from Participant Workshop

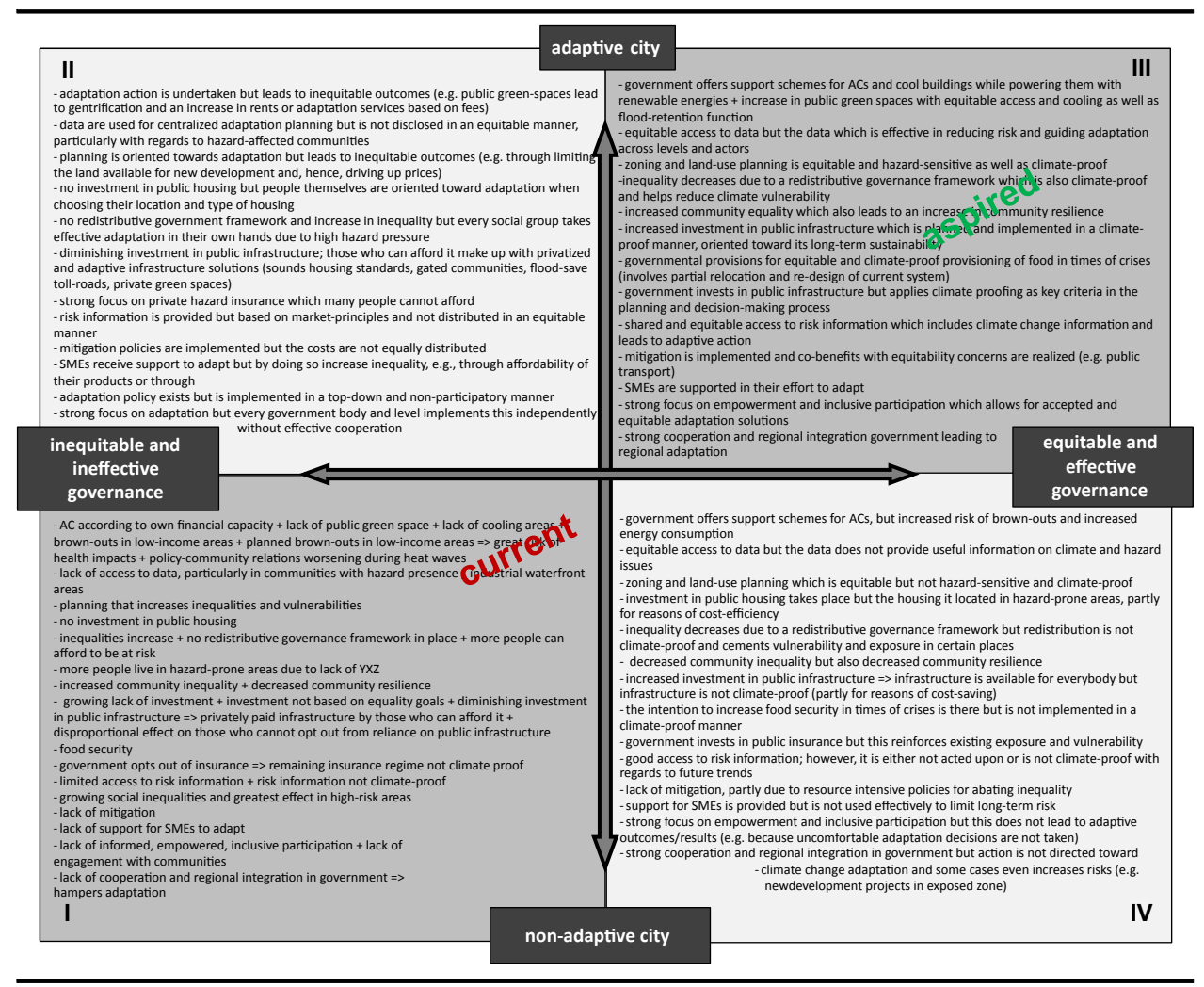

The participants felt that the city currently occupied the quadrant associated with increasing inequity, declining governance capacity and non-adaptive characteristics, this included a lack of capacity to coordinate government activities and programs, critical information and knowledge on risk, vulnerability and benefits of adaptation strategies, declining expenditure in new public infrastructure and declining quality of existing infrastructure. The participants consider a more adaptive and equitable city with more greater governance capacity to be associated with the opposite of these factors. The workshop participants were quite aspirational for the New York City and its capacity to respond and meet the challenge of climate change. This optimism is consistent with the city's history overcoming other environmental challenges (Solecki 2012). In this scenario, the City's climate adaptation and mitigation strategies would be co-aligned to promote co-benefits. Other quadrants were characterized either by enhanced climate adaptation but with responses that would be led to and further the current trajectory of greater 
inequities. The fourth quadrant included strategies that would foster greater equity and governance capacity while forestalling movement toward greater climate adaptation.

Results from analysis of surveys corroborate data collected during the workshop. Experts surveyed identified New York City government highest risk management priorities as coastal flooding, heat waves and terrorism. The autumn 2015 terrorist attack on Paris were figured prominently in the interviews. Figure 1 below shows a majority of survey participants identifying resilience and resistance as the dominant New York City Risk management regime. Across various hazards, the overall assessment of current risk management is evenly split between resistance and resilience. Transformational risk management or collapsed risk management regimes were very rarely mentioned, and only in response to particular hazard regimes. On further probing several risk managers noted that there were varying strategies to address different urban risks.

Figure 2 shows survey participants perceptions city government risk priorities. Separating terrorism out of the analysis based on bias issues was discussed earlier, survey respondents most frequently opined that city government held flooding, both coastal flooding and rainfall flooding, and heat waves to be the most important hazards. Heat waves were most frequently identified as a very important hazard, followed by rainfall flooding and street crime. ${ }^{5}$ Further discussion with interviewees reiterated differences between risk management regimes for heat and flood risk. The infrastructure-oriented flood and storm surge risk policy of the past for many respondents was an expression of a risk management regime oriented

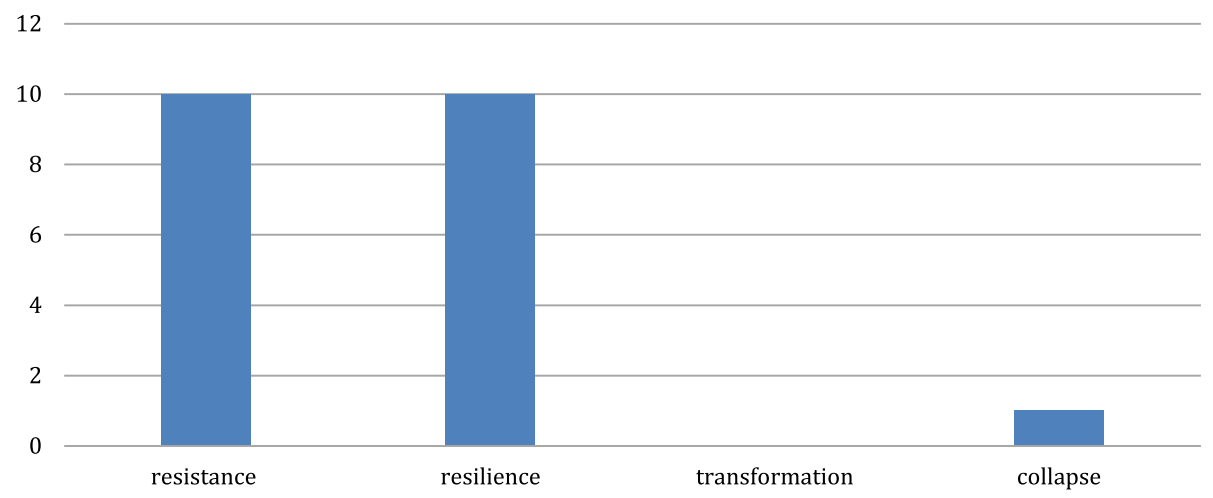

Figure 1. Current Dominant Risk Management Regime in New York City

\footnotetext{
${ }^{5}$ Street crime has been a real or perceived risk in NYC for decades, and typically eclipses concern for terrorism.
} 


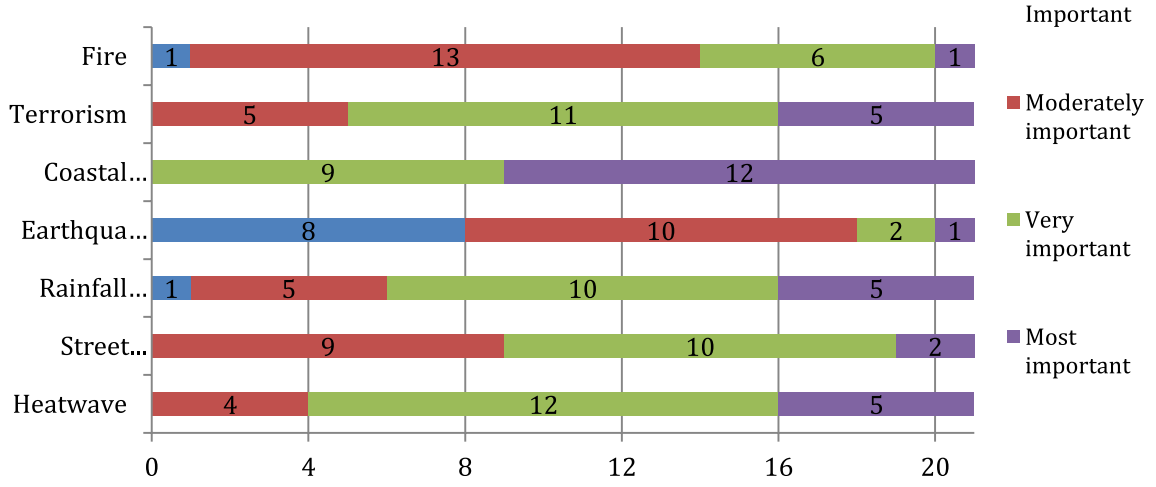

Figure 2. New York City Hazards, Perspective of City Government

toward resilience, whereas heat risk management policies focused on individual behavior (http://www1.nyc.gov/assets/em/html/beat-the-heat/beattheheat.html) is perceived to be more oriented toward resistance.

Responses identifying the influential factors in New York City risk management policy show a multiplicity of factors are present. In Figure 3, city political priorities and economic inequality were mentioned most frequently as a very large influence. Business concerns, agency risk management capacity, effective communication, and dissemination of hazard information tied as the next most frequently cited factors with very large influence. Hazard information and city political priorities also were the factors most frequently cited as having large influence on city risk management policy. The influence of these factors is consistent with major drivers identified in the May 2015 workshop. While none of the survey participants explicitly mentioned the influence of business on city politics or the tensions emerging from the current Mayor de Blasio's “Tale of Two Cities” mayoral

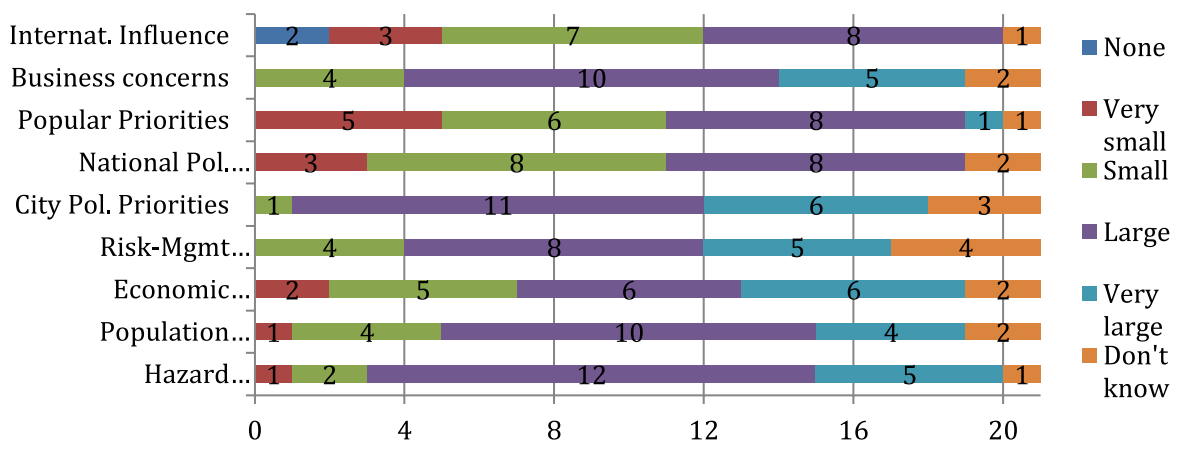

Figure 3. Factors Influencing Current New York City Policy 
campaign, it was understood that real estate developers dominate the land use discussion. Hazard information emerged from the surveys as an important influence on current risk management policy. A total of 17 out of 21 surveyed persons identified hazard information as either a large or a very large influence. In the context of this study, hazard information includes both access to information and an ability to integrate available information into actionable policy.

The variation in risk management regime across major types of risks and hazards identified within NYC warrants further analysis. During the workshop sessions, participants noted the impact of social inequality and poverty on risk management and planning. The global city position of New York highlights the extreme variation in access to urban resources from services to housing opportunities along the affluence scale. Survey participants suggested that the nexus of increased social inequality and increasing heat wave and flooding frequency could have dire political consequences. With this in mind, the current risk management regimes for flood and heat wave risks will be examined in depth.

Coastal floods and storm surge

For coastal flooding and storm surge risk in New York City, perception of the risk management regime was almost evenly split between resilience and resistance orientation. Many respondents saw the quick response to Hurricane Sandy in the utility and urban planning sectors as an expression of a resilience paradigm, exemplifying how the urban administration can be nimble and responsive in cases of extreme need. Many experts cited the lack of more robust restraints on shoreline development as indicative of finance, insurance and real estate (FIRE) driven orientation toward resistance based risk management. While recent zoning changes for structures in evacuation zone 1 were cited as examples of good governance, there was a strong sense that risk from storm surge in New York City is egregiously understated. One respondent stated, "My concern is that a lot of the hazards are not being addressed in any real and robust way".

This view was consistent across different levels of governance. Another respondent mentioned that, "Critical mass of flood risk awareness has not been reached. We (NYC) are currently responding rather than having buy in for changing our regulations in the city's floodplain.” Respondents also noted that attitudes toward risk management also might be influenced by economics and geography, expressing the stark relations between wealth and location in the city. Non-affluent areas in the outer boroughs hard hit by Sandy are more oriented toward changing current planning and business practices. A perception exists that stakeholders in the ultrahigh rent waterfront areas of Manhattan are more likely to take a resistance stance. 
The resistance-oriented risk management regime for floods in New York City also can be traced to the economic value of waterfront properties in New York City. Prices for new development and housing are increasing dramatically in New York City. The economic value of waterfront property and the presence of many great wealthy owners in New York City are drivers perceived to support a continuation of resistance-oriented risk management. One participant noted a sentiment echoed by many survey participants.

"Threats of economic loss are among the significant barriers to change. [The economic value of development near the water] "creates incentives to continue a policy of building in floodplains, even though climate change projections indicate more frequent and severe flood events.”

Commitment to continued development near the water is reflected in recent flood risk management policy in New York City. The City of New York risk landscape Chapter 4.3 (NYCS risk landscape, Chapter 4.3 flooding) on flooding refers property owners and managers to the New York City Department of Buildings code standards for flood resistant construction in accordance with federal mandates. The risk landscape document states,

"Well before Hurricane Sandy, structural measures to protect properties prone to flooding were being implemented. Post-Sandy, these efforts have expanded to include integrated flood protection systems, increased coastal edge elevation, and protection of infrastructure and critical services.” (p. 82 ibid).

The current flood risk management approach includes a proposed, large new flood protection and urban development plan in a lower Manhattan - an area that was heavily impacted by Hurricane Sandy. The proposed project includes a two-kilometer, multi-purpose levee structure that includes extensive new residential and commercial development within close proximity to the Wall Street financial district. As discussed, based on available data, risk management in these areas are currently characterized as in a state of resistance; however, there is potential for these core areas to transition to spaces of resilience or transformation in the future. Conversely, it would also be possible that collapse is a potential adaptation pathway space of the city's core in the future if maladaptive behaviors occur (Solecki et al. 2017). While technologically innovative and requiring considerable economic investment, the orientation, with regard to development trajectory in the city's economic and geographic core, is firmly in the mode of resistance, 
development assets are protected (arguably enhanced) and development activity is not interrupted or deviated by risk management.

Additionally, the City of New York has implemented a host of programs that encourage landowners to build back differently (http://www.nyc.gov/html/recovery/html/homeowners/rebuild.shtml). For the most part these initiatives target the middle class, working class and non-affluent population of the city in low-lying areas of the outer boroughs. While these policies indicate innovation in technology and supporting institutions, the geographic differences in application reveal an orientation of resistance - development is to be protected and may be enhanced - but is not to be problematized (i.e., made a political issue) through risk management. Despite the concerns voiced by experts surveyed, little evidence exists of a New York City policy aimed at retreat from the waterfront. Indeed, at the time of writing, several large residential projects are underway on the shores of the city's most at risk and contested waterway, the Gowanus canal in the borough of Brooklyn. Construction has begun on the Beach Channel senior housing project in one of the most severely impacted parts of the city during Hurricane Sandy, Rockaway Queens (NYC Office of the Mayor 2015).

The New York City post-Sandy Build-it-Back program (see www.nyc.gov/html/ recovery/html/homeowners/rebuild.shtml) is driving an aggressive re-commissioning program for impacted waterfront structures with rudimentary provisions for limiting damage from future flooding limited to geographies where homes were destroyed. Economic pressures in the city's downtown commercial and financial center, interests and housing demands in the outer boroughs experiencing population increases effectively dominate the decision making process and policy making agenda. A mix of investment in real estate and land use development lead to risk policy inertia particularly in the waterfront area of the city. The driver of these tensions is the commodification of residential real estate and the collapse of the non-service economy in New York (and in many global cities). It has been many decades since New York City was the capital of small luxury goods manufacturing (Wolf-Powers 2005). With the collapse of the design and atelier economy, one of the few remaining business sectors in New York City is real estate.

Residential real estate in global cities is seen as good investments, safe places to park money for international investors (Pow 2016; Fernandez et al. 2016). In the context of risk management, New York City business is first to be protected. Furthermore, New York City like many global cities is experiencing continued population growth. (NYC Department of Planning 2013). The current de Blasio administration has committed to eliminating the "housing crisis" in the city (NYC 2016 Department of Housing). One of the strategies employed is building public 
housing on abandoned industrial and government real estate (NYC Department of Housing 2015). Unfortunately, a number of these parcels are also high flood risk property with limited access to the public transport grid of the city center (NYC Department of Housing 2015). In general, it has become clearer that there is a growing difference between the strategies lower Manhattan central business district stakeholders are using to manage coastal storm risk and those used in coastal areas of the outer boroughs. Lower Manhattan is focused on a variety of engineered resistance and resiliency measures while the outer boroughs have been the focus of buy out programs and individual property resiliency efforts including incentives to raise houses.

\section{Heat waves and heat stress}

A majority of respondents indicated that heat waves are currently either important or very important to the New York City Municipal Authority. A total of 16 experts surveyed agreed or strongly agreed that the current orientation of the risk management for heat waves in New York City as resistance. In a separate set of questions, 11 participating experts felt that the NYC risk management for heat waves was oriented toward resilience (agree or strongly agree). Nine responded that the city approach to manage heat-wave risk was oriented toward transformation (agree or strongly agree), and four experts surveyed indicated that city heat wave risk management policy was in collapse (agree or strongly agree). For those primarily concerned with heat wave risk, there was a sense that heat wave risk is inadequately managed. "Heat is underestimated as a stressor, street livability focuses on crime because they have the police and it focuses on specific populations," noted one respondent. And "with heat waves, the data tells us there is a great risk but New York City resources have not been allocated. Medium level longer term heat risk has not been assessed,” answered another interviewee.

Based on participant responses and emergency preparedness information published by the City of New York emergency preparedness agencies (IBID Beat-the Heat) a great deal of heat wave risk management policy is reactive and focused on personal behavior. The city opens cooling centers when ambient temperatures reach $95^{\circ} \mathrm{F}$. City government emergency response outreach encourages citizens to watch for the signs of heat related illness and check on their neighbors. Participant responses suggest that low political accountability limits popular and political will for transition, or even for action beyond the reactive.

"An important factor influencing the lack of focus on heat is political attribution risk. Most heat related deaths are anonymous without any political leader's name on it. The public are not frightened by heat even though every year deaths caused by 
extreme heat are greater than the deaths caused by Sandy's coastal flooding. The difference is a result of backwards looking risk perception.”

Participants also expressed the urgent need for broader acknowledgement of the heat problem and a more integrated policy. The current heat adaptation regime is characterized by intentional underdevelopment of an integrated regime; collapse. This urgency suggests a move from collapse to resistance.

"We need to change policies and energy subsidies around air conditioning access for vulnerable people. We need to look at the current building stock and current construction for their thermal performance, determining which buildings perform well and which do not provide thermal comfort in extreme heat event especially if there is a power outage. We need to consider the extent of use, misuse and overuse of air conditioning in high-end buildings and the associated externalities.”

Even with the substantial body of knowledge on the science of urban climates little evidence exists that this knowledge is incorporated into urban planning and design practice (Mills et al. 2010). Throughout the interviews, little to no mention was made of changing patterns of development or urban morphology to mitigate the heat retention properties of urban structures nor was there any discussion of New York City's white roofs initiative or the heat reduction impact of green infrastructure. The current narrative of heat risk in New York City seldom includes infrastructure vulnerability during extremely hot weather. This gap in the response re-affirms the NYC heat risk adaptation regime as one of resistance. That urban form never or rarely enters the discussion and also supports two other recurring themes in participant response: (1) Accumulated knowledge about climate risk has not been effectively communicated to decision makers; and (2) Altering urban form seems largely unachievable because it requires buy in of the real estate industry (and by extension the finance and insurance business community), and as a result it has been dropped as a viable policy issue.

\subsection{Potential of transition to a new risk management paradigm}

The condition of a potential transition to a new risk management paradigm in New York was discussed in the workshop and with the expert project participants. Most survey participants noted the extreme and problematic mismatch between the City's risk management response and the risk of extreme weather, sea level rise and associated flooding. The majority of New York City workshop participants viewed 
the current risk management approach as somewhat rigid. They also noted some prevalence of inequitable and ineffective governance. The majority workshop participants also saw the city drifting toward a further loss of social and economic equitability and effectiveness in governance, and viewed risk management initiatives recently launched by the current mayoral administration with ambivalence.

Considering the potential near term impacts of these initiatives, the participants could envision the city, shifting course to a more equitable and effective governance regime. While these policies are designed to decrease future climate risks and improve the adaptive capacity, some workshop participants contested this outcome. They argued that the unintended side effects of these policies would harden current unsustainable high-risk patterns of development, decreasing longterm city adaptive capacity. Regardless of potential negative near term effects, the workshop participants enthusiastically agreed on the long-term value of urban governance characterized by high adaptability and increased socio-economic equality (Garschagen et al. 2017).

The expert interview results corroborated the workshop results. Survey data suggest that there is awareness in New York City of the need for a transition toward more transformative adaptation and a degree of confidence that transition can be accomplished. A total of 17 out of 21 participants indicated that the minimum change expected in the next generation is an aging population coupled with increased heat wave and flooding risk. A total of 14 out of 20 participants indicated that there were conditions for transition. Eight said the transition would be toward resilience, six said the transition would be toward transformation. Acknowledging the need for transformative climate change adaptation was stemmed partly from a robust awareness of the probability of increasing extreme storm events and the already problematic high tide flooding in waterfront neighborhoods of the city (such as Broad Channel in Jamaica Bay which also was severely flooded by Hurricane Sandy).

Over half of respondents expected that within the next 20 years, New York City will face not only changes in environmental and biophysical hazards (more floods, more heat waves), but that socio-demographic changes will aggravate the risk scenarios for the city. Further expert responses shed light on additional compounding factors for the scenarios articulated above. Compounding factors cited most frequently are increasing population in all age groups, deteriorating infrastructure and the impact of climate change and extreme weather on the New York City water supply system. One respondent noted that "in addition to an aging population, there will be increased population in general plus aging and failure of critical infrastructure”. Two-thirds of the surveyed risk managers predicting regime 
change see regime changing from resistance to resilience or resilience to transformation.

Questions aimed at revealing expert awareness of the need for change in responses to different risk scenarios revealed the following; For each of the four scenarios (A: more heat/flood events; B: more heat/floods + aging population; C: more heat/floods + aging population + social inequality, D: more heat/floods + aging population + social inequality + diminished governance capacity) respondents were asked to consider if the current risk management regime would be adequate to manage the scenario, or if minor or even major changes would be needed to the current risk management regime, and if so, of what type these were. Figure 4 shows the distribution of answers for the starting scenario from which onward respondents considered major changes as necessary to address risks in New York City. All participants who answered this question thought that major changes to risk and adaptation planning in New York City were inevitable at some point in the next 20 years. Results show an inconsistent picture of the starting point from which major changes would be needed to address future risk scenarios in New York City.

The graphic highlights a bimodal distribution of answers, with Scenario A (more heat/floods) and Scenario C (more heat/floods + aging population + social inequality) being most often considered the starting point for major changes to risk and adaptation planning in New York City. Over half of respondents felt that geophysical hazards alone were not accurate in describing future risk. Socio-demographic vulnerability was recognized as an important driver of transition. Seven respondents also felt that aging alone might not lead to revised performance but that inclusion of economic inequality would be required to drive transition. As our

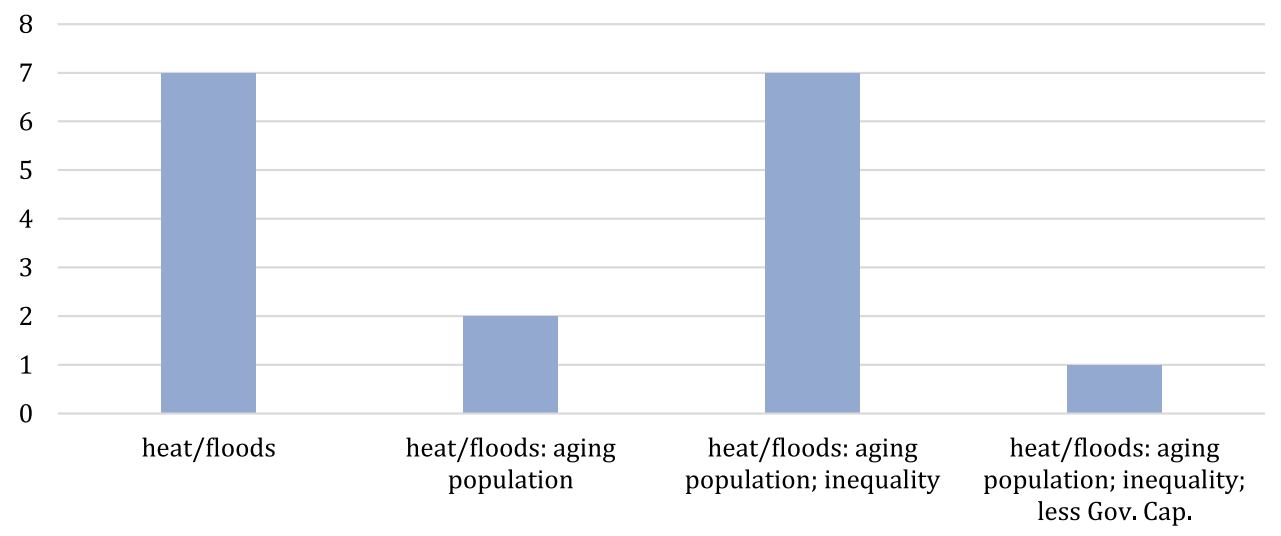

Figure 4. Starting Scenario for Major Changes in Risk Management 
research strives to identify thresholds for major change, this set of responses suggest that NYC is very sensitive to the combination of inequality and an aging population but also to increased hazard itself. For some, business as usual can cope with more geo-physical hazard but not with an aging population or the more extreme socio-economic changes of increasing income inequality that is generally perceived of as being "bad for business." For others the need for major changes will appear with increased physical hazards. These results suggest different vulnerabilities to climatic factors, and demographic and socio-economic factors, as tipping points for transformational adaptation regime change.

Considering the four scenarios as a continuum, it is difficult to pinpoint either a definitive climatic or socio-economic catalyst for transition toward transformation in New York City. These results may be interpreted that the climatic threshold for change has already been crossed but the socioeconomic threshold is at increased income inequality. This interpretation is corroborated by respondent remarks about lack of public awareness of coastal flooding risk quoted earlier in this paper. One participant responded to this suite of questions saying:

"We need to think at the level of the threat we are actually under.

We need to acknowledge the level of threat. The level of threat is

7; our response is level 3"

It may also be that NYC risk management is keeping within publically acceptable levels of risk. Elements of the stakeholder community ascertain that because proximate causes of flood and heat risk are currently dealt quite well, the need for transition to resilience let alone transformation is in the distant future. In this paradigm, the opportunity costs of risk management transition are temporarily avoided, externalizing threat and costs to the future when transition will be more likely to be forced.

\subsection{The process of risk management transition}

This section examines how a risk management transition can be enabled or blocked by the current actors, organizations and policy-making networks for adaptation and risk management in the city. Both workshop and survey participants expressed the need for risk management regime transition. The obstacles to and accelerators of risk management regime change identified were remarkably consistent across both workshop and survey datasets.

The extent of city government and the public sector mediation of changes in risk management and socio-economic development were subject to robust debate in the workshop. Workshop participants concluded that the most powerful forces shaping 
future trajectories of risk and adaptation reside in the administrative domain, rather than in technical or geo-physical changes. The rights and responsibilities of risk management, especially at the nexus of government and non-government domains, evolved as the dominant theme. The questions of how to create change and who will create it are inextricably linked to issues of equity and social justice.

Similarly, for survey participants, city politics was identified most often as having the most impact on New York City risk management policy-making. The Mayor and the mayor's office were cited in two-thirds of the responses as primary drivers of change in city hazard/risk management. The real estate and associated finance and insurance industries were also identified drivers of city risk management change. Survey participants were passionate and exasperated at the extent of business and private sector impact on risk management policy. "No-one should ever underestimate the impact of banking and finance on policy in New York," stated one respondent. More than half of survey participants perceived the ability of city agencies to respond to risk and hazard information to have large impact on city risk policymaking. The role of a single leader was seen as critical in this context. The work of the Michael Bloomberg as Mayor of New York from January 2002 to the end of 2013 has been as critical to the city's climate action efforts and leadership (Solecki et al. 2016; Bagley and Gallucci 2013). In a departure from the workshop discussion, experts surveyed also identified scientists and academics as key actors shaping risk management policy (see Figure 5).

The results emphasize that finding the "right" risk management regime for a city is above all political processes, while designing the concrete risk management infrastructure, both hard and soft, is often secondary. Climate risk topics have long been part of the public dialogue in New York City. The workshop, however, revealed significant disconnects. Experts noted that previous responses to climate

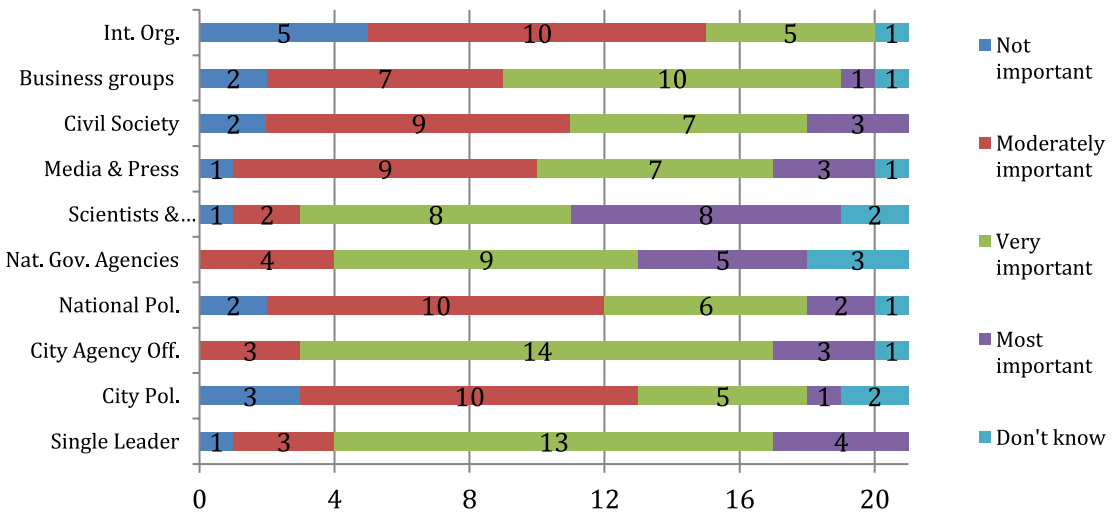

Figure 5. Actors Influencing Change in Current New York City Risk Management Regime 


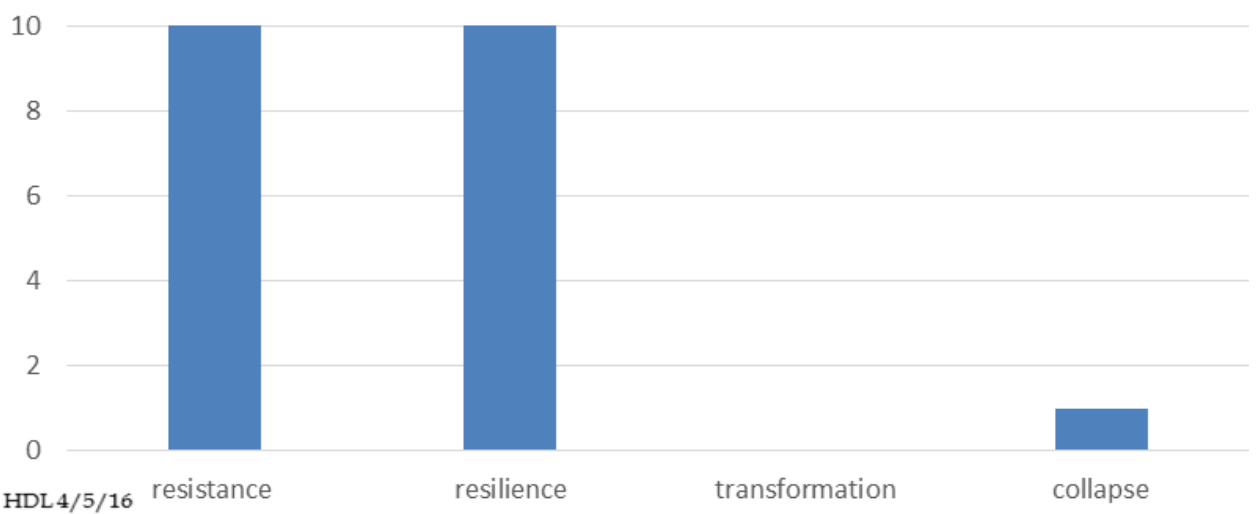

Current Direction of Change in NYC Risk Management

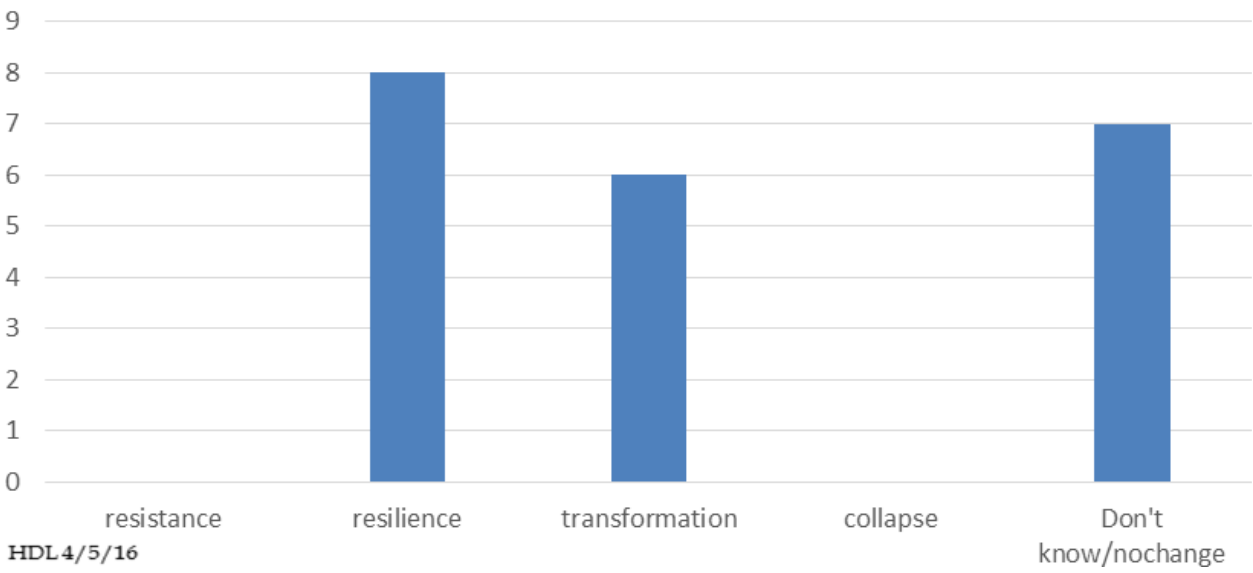

Figure 6. Expected Direction of Change in Risk Management

risk have been compartmentalized. Survey participants identified this issue also and commented, "Considerations about risk management are more silo-ed than they need to be. Different concerns need to be more integrated." Survey participants cited a silo-ed and disconnected agency responses as a barrier to effective planning and policy setting.

A number of workshop participants identified a tendency to block out the core implications of climate risks for the larger development trajectories of the city. One expert in New York City captured this concern by saying that "the fundamental issue is a lack of acknowledgement of what we are heading toward. Beautiful maps 
show sea level rise and describe impacts, but at our core we can't acknowledge that we have to fundamentally change how we live in New York City.” These conclusions of workshop participants mirror the points raised in an expert interview.

"We will need to acknowledge that there is too much risk to inhabit some areas. All of this must take place against a background of a political system where there is a lot of potential turnover and tremendous flux. Political and institutional turnover makes paradigm shifts and long-term decision making difficult. Currently a change of administration can kill the momentum of a decade of public risk management policy development. Certain institutions need to function beyond a business plan time frame.”

Risk communication

Risk communication was characterized as an important stumbling block to moving beyond resistance-based risk management policy. Survey participants emphasized disconnect between agencies responsible for risk management and an inability of city agencies to speak in one voice. Several participants spoke about the difficulty of translating disaster risk knowledge into policy due to a lack of risk perception. One respondent stated that, "there is the strong sense among many stakeholders that Sandy was an aberration.” Another participant noted, "Policy changes don't begin until there have been at least two extreme weather events over a three year period”. More than half of the experts surveyed identified risk communication as an issue with large influence on NYC risk management policy. Risk communication in this context includes the ability of city agencies especially social service agencies to translate climate change data into actionable risks and or policies. "Flooding is managed on an ad hoc basis. City spending on flood protection does not match the coastal flooding risk."

Survey participants comments on risk communication relate to the workshop observation that much current work on climate risk projects is abstract and make the problem largely technocratic. Current city climate change efforts focus on assessing and mapping potential future hazards. The deeper social and cultural questions of how the population and administration of a megacity like New York is able and willing to fundamentally alter established ways of life remains largely untouched.

This highlights the need for scholarship on and outreach to key non-technical stakeholders and facilities managers such as New York City Housing Authority that manages the public housing buildings in the city (which includes approximately 178,000 apartments as of mid 2016). Climate science data must be made 
accessible to the non-science community to enable prescient decision-making on the social impacts of extreme weather and coastal flooding.

The character of transformational change

A key challenge for transformation is uncertainty in its policy goals and aims. Transformation can take place within individual values, specific sectoral activities local and national legislation, or global political-economic systems (Solecki et al. 2017). The most frequently offered interpretation of transformation within the interviews was a retreat from the shore. These short quotes and longer quote reflect this sentiment: "Coastal development must be limited. The current coastal risk policies encourage private development;" "formalized buyout strategies must be incorporated into coastal communities to transform the way we engage the waterfront," and "we need to radically rethink settlement patterns."

"A critical mass of awareness has not been reached. We are still in a responding mode rather than having the political buy-in for changing our ability to have better regulation in the city's floodplain. We need a more flexible, more strongly enforced culture of construction in the floodplain and there needs to be funding for residential and commercial stakeholders in the floodplain to make the necessary adjustments themselves.”

These responses illustrate transformation of local shore properties, their market values, and the lives of their owners; but they are less transformative of root causes in city policy or in underlying balance of power between the vested interests in the city. Shoreline retreat captures the tensions in transitions to transformative adaptation that must address both the FIRE business sector demands for a stable development environment and realities of increasing waterfront vulnerability. In New York City, tremendous pressure exists to open any and all areas for increased development. Current social inequality creates lower socioeconomic status neighborhoods in highly flood vulnerable areas. Survey participants' responses suggest a sense that increasing social inequality will drive the non-affluent deeper and deeper into highly flood prone areas.

Growing social inequality was seen by all but one New York City expert as a challenge that would require fundamental changes to risk management strategies. Enhancing neighborhoods, building community response capability and finding new service delivery paradigms were identified as possible management strategies for the extreme socio-economic failure scenarios. Some respondents opined that in the scenario of a $50 \%$ reduction of government funding, social collapse would ensue. "With a 50\% reduction of funds no incident response would be successful. 
Existing protocols would be insufficient and the actual response would not be successful, would be a failed response". Another expert wondered if "representative democracy is strong enough to manage such a calamity". In several cases the prospect of decreased governance capacity seemed to elicit an inability to process. Participants simply responded that "more funds would be needed" or "government intervention would be required.”

Transformative regime transition: Opportunities and barriers

The need for adaptation regime shift expressed in both the expected future risk scenarios for New York City and the perceived inadequacy of current risk management practices to address such future risks, is paired with pragmatic determination to do whatever it takes.

About two-thirds of the participants indicated that "there is public sentiment for change" in the present aims for risk reduction policy. Some indicated that change is proceeding at different paces for each hazard or that change is moving at varying rates in different parts of the city. Factors influencing the rate of change included "fear of change and business interests and the notion that inequity is not good for business". One participant felt that change is moving too slow, "Development pressures are impeding the direction of change". Differences of opinion, "the continued disagreement over "grey engineering" and nature based solutions" and public understanding of engineering solutions to flood management was also identified as slowing regime change. The powerful and omnipresent real estate industry was hinted at obliquely in interviews as "business interests", "differences of opinion”, and "development pressures." While interview participants signaled a striking desire for change in New York City, land use decisions were seen as driven by the value of real estate and the demand of real estate interests that their investments be protected. Efforts to manage development in high-risk areas at the local planning boards are frequently pressed back by real estate representatives (i.e., their legal teams) (Lederer 2015). Overall, the sentiments and stalled impulses revealed in this section of the survey echo that of the wider sustainability literature. Opportunities to bring climate protection into policy implementation are often undermined by mainstream visions of development and transport planning (Bulkeley and Betsill 2005).

\section{Conclusion}

The intricate process that the City of New York publically describes as "resilience" includes a variety of local drivers and contextual factors. The analysis shows that across hazards, a number of respondents from various administrative scales characterized current risk management approaches in New York City as resilience 
oriented. Almost an equal number of respondents characterized city risk management approaches as resistance focused. Risk management for floods in New York City was characterized as resistance-oriented or resilience oriented depending on economics and geographic location. The economic value of city center, riverside property rendered more preventive land use strategies financially unviable. The economics of Wall Street and the global city shaped resistance based largescale infrastructure solutions like the inner harbor seawall. Zoning changes in working class and poor, ocean front communities such as the Rockaways suggest resilience-based risk management. Civil infrastructure alterations such as street lifting in the Jamaica Bay community of Broad Channel reinforce the perception of resilience-based risk management far from the global economic hub.

In contrast, risk management for heat was predominantly characterized by behavioral, rather than infrastructure-centered approaches. Respondents characterized the development of the New York City heat wave task force last year as a resistance management regime change. While awareness of heat risks exist, the heat vulnerability demographic and the focus of climate change scholarship limits more aggressive heat risk mitigation strategies. Lack of data on the effectiveness of retrofitting existing building stock in New York City for heat risk mitigation constrain (physical) adaptation to heat wave risk in the city.

New York City presents limited opportunity for a transition toward transformational adaptation. Although all respondents acknowledged a need for fundamental changes to meet expected future risk scenarios, the focus of existing New York City policy transition was, in most cases, toward resilience. Overall the results from the analysis suggest that there is a will to change in New York City and that the difficulty lies in creating a workable business model or public/private partnership for the necessary transformation.

A range of factors was identified that constrain the prospects for transitions in New York City. Most importantly these include silo-ed and fragmented governance in local New York City administration, where multiple lines of responsibility coexist for a single asset or outcome, and an incompletely integrated system of risk management regimes, where individual organizations and stakeholders are responsible for developing and maintaining individual management approaches. Ineffective communication and integration of heat and flood risk into New York City land use decisions results in a failure to integrate credible risk-based costs into urban policy cost-benefit analyses. The absence of finance, insurance, and real estate stakeholders, who are the mainstay of the New York City economy, from the formal risk management discussions is another key limiting factor. This is particularly problematic as the majority of participants cited the finance, insurance, and real estate nexus as one of the primary constrictions to risk management 
regime change. The exigencies of the bureaucratic process and electoral politics also hamper risk management transition. Participants cited the intricate, convoluted, and time-consuming federal coastal resilience funding as a negative factor. Furthermore, elected decision makers have a brief time to create impact. Forcing policies that could be described as "bad for business" is perceived as a threat to electoral job security.

Workshop and interview respondents characterized risk management regimes in New York City as fairly resistant to change. The tension between political demands that risk planning provide tangible outcomes and visible benefits and the difficulty in translating highly nuanced climate data into actionable policy is slowing the pace of regime shift. Political support and resources necessary to innovate risk management approaches and drive regime change seemed available only in response to significant events that focused public attention and required a visible response from public authorities. This short-term mind-set systematically undermines efforts at long-term preventive risk planning. Forward-looking strategies to mitigate risk do not offer the same visible output as emergency preparedness. Planning and preparation are seen as less glamorous and heroic than emergency response, and is more difficult to fund.

Finally, New Yorkers interviewed were remarkably sanguine about their ability to stave off the scale of social inequity that could lead to wholesale upheaval. Substantial concern exists about a loss of heat and flood risk management funding. Survey participants either did not register funding reductions in their responses or fear the worst, hyperbolizing political collapse.

\section{Acknowledgment}

Research reported on in this paper was undertaken as part of the Belmont Forum funded Transformation and Resilience on Urban Coasts (TRUC) project. This project was supported by Japan Society for the Promotion of Science, the UK Natural Environment Research Council and Economic and Social Research Council (NE/L008971/1) the German Research Foundation (GZ: BI 1655/1-1), The Ministry of Earth Sciences, Government of India (MoES/01-CZM/Truc/ 2013) and US National Science Foundation (1342966).

\section{References}

Bagley, K and Gallucci M (2013). Bloomberg's Hidden Legacy: Climate Change and the Future of New York City. 
Bagley, K, Gallucci M, McKenna P, Lavelle M, Shankman S, Kaufman L, Song L, Kusnetz N, Berwyn B and Hirji Z (2013). Bloomberg's hidden legacy: Climate change and the future of New York City, Part 5. InsideClimate News. N.p.

Bulkeley, $\mathrm{H}$ and Betsill $\mathrm{M}$ (2005). Multilevel governance and the 'urban' politics of climate change. Environmental Politics, 14(1): 42-63, doi: 10.1080/0964401042000 310178.

Fernandez, R, Hofman A and Aalbers MB (2016). London and New York as a safe deposit box for the transnational wealth elite. Environment and Planning A, $0308518 X 16659479$.

Gaffin, SR, Rosenzweig C, Khanbilvardi R, Parshall L, Mahani S, Glickman H, Goldberg R, Blake R, Slosberg RB and Hillel D (2008). Variations in New York city's urban heat island strength over time and space. Theoretical Application Climatology, 94: 1-11. DOI 10.1007/s00704-007-0368-3.

Garschagen, G, Pelling M, Solecki W, Agboola J, Narayanan P, Birkmann J and Ajibade J (2017). Future in the making: Transdisciplinary scenario development for pathways of climate risk and transformative adaptation in coastal megacities. Global Environmental Change, under review.

Kiersz, A (2014). Here's a block-by-block look at who's making how much across NYC's 5 boroughs. Business Insider, 11 December.

Lederer, K (2015). Why Buy in a Flood Zone? The New Yorker, 6 July.

Mills, G, Cleugh H, Emmanuel R, Endlicher W, Erell E, McGranahan G, Ng E, Nickson A, Rosenthal J and Steemer K (2010). Climate information for improved planning and management of Megacities (Needs Perspective). Procedia Environmental Sciences, 1: 228-246.

NYC Department of Housing (2016a). Housing_plan.pdf. Available at http://www.nyc.gov/ html/housing/assets/downloads/pdf/. NYC.gov, Web. 29 November 2016.

NYC Department of Housing. Housing Problem (online) (2016b). Available at http:// www1.nyc.gov/site/housing/problem/problem.page. NYC.gov, Web. 01 December 2016.

NYC Department of Planning (2016c). Population Projections, By Age/sex \& Borough, and 2010-2040. 2010202020302040 (n.d.): n. pag. Web. 01 December.

NYC Emergency Management, NYC Department of City Planning and NYC Mayor's Office of Recovery and Resiliency. NYC Risk Landscape: A Guide to Hazard Mitigation, Chapter 4.3 Flooding. (online), Available at https:/www1.nyc.gov/assets/ em/downloads/pdf/hazard_mitigation/nycs_risk_landscape_chapter_4.3_flooding.pdf.

NYC Office of Emergency Management. Beat the Heat $\mid$ NYC Office of Emergency Management. Web. 01 December.

NYC Office of the Mayor. Build It Back Program. NYC - Rebuild Program (online), Available at http://www.nyc.gov/html/recovery/html/homeowners/rebuild.shtml.

NYC Office of the Mayor (2015). Mayor de Blasio, Queens officials and the Arker Companies break ground on 154 new affordable homes for low-income seniors, Available at http:// www1.nyc.gov/office-of-the-mayor/news/569-15/mayor-de-blasio-queens-officialsthe-arker-companies-break-ground-154-new-affordable-homes).

Pelling, MJ and Abeling MG (2016). Emergence and transition in London's climate change adaptation pathways. Journal of Extreme Events, in press. 
Pelling, M (2011). Adaptation to Climate Change: From Resilience to Transformation. New York: Routledge.

Pow, CP (2016). Courting the 'rich and restless': Globalisation of real estate and the new e]spatial fixities of the super-rich in Singapore. International Journal of Housing Policy, Available at http://dx.doi.org/10.1080/14616718.2016.1215964.

Sassen, S (2005). The global city: Introducing a concept. Brown Journal of World Affairs, 11: 2 .

Solecki, W (2012). Moving toward urban sustainability: Using lessons and legacies of the past. In: Zeman F (ed.), Metropolitan Sustainability: Understanding and Improving the Urban Environment, Sawston, Cambridge, U.K.: Woodhead Publishing, pp. 680-696.

Solecki, W, Rosenzweig C, Solecki S, Patrick L, Horton R and Dorsch M (2016). New York, United States of America - case study. In: Bartlett S and Satterthwaite D (eds.), Cities on a Finite Planet. Transformative Responses to Climate Change. London: Routledge.

Solecki, W, Pelling M and Garschagen M (2017). Transitions between risk management regimes in cities. Ecology and Society, under review.

Tan, J, Zheng Y, Tang X, Guo C, Li L, Song G and Chen H (2010). The urban heat island and its impact on heat waves and human health in Shanghai. International Journal of Biometeorology, 54(1): 75-84.

Wolf-Powers, L (2005). Up-zoning New York City’s mixed-use neighborhoods propertyled economic development and the anatomy of a planning dilemma. Journal of Planning Education and Research, 24(4): 379-393. 